\title{
RESEARCHES
}

on

SOME POINTS

\section{OF THE PATHOLOGY}

or

\section{PULMONARY TUBERCLES.}

By PETER NUGENT KINGSTON, M.D., PhYSICIAN TO THE ST. GEORGE'S AND ST. JAMES'S DISPENSARY.

READ MARCH 28TH, 1836.

So large a portion of the human race fall victims to pulmonary tubercle, that too much time and attention can hardly be employed in perfecting its diagnosis, prognosis, treatment, and prophylaxis. Little further progress can be made towards this end until the pathology of the disease has been accurately developed *. My present design is to shew, 1st, that the common pulmonary tubercle is a vascular texture; 2dly, that it sometimes originates in an alteration of the air-cells and their secretions ; and 3dly, that now and then it

* "The utmost exertions of the British practitioner," said Dr. Abercrombie, in 1821, "will be amply rewarded, if any degree of precision can be introduced into the pathology of consumption. At present it is certainly vague and unsatisfactory in the greatest degree."-Edinburgh Med. and Surg. Journal. 
is entirely healed, when it has even extended over a very large portion of the lungs.

\section{I.}

The opinion that pulmonary tubercles are destitute of nutrient vessels, and consequently of all the propertics of organization, originated about half a century ago with Stark. It has since been held by the majority of pathologists, and prevails in the present day. I shall nevertheless endeavour to shew that the facts on which it rests do not warrant such an inference; and shall adduce a number of cases in which the vascularity of the common pulmonary tubercle admitted of ocular demonstration.

The principal ground on which the vascularity of pulmonary tubercles has been denied is, that they cannot be injected from the vessels of the lungs. Thus, Dr. Alison, one of our most judicious pathologists, observes, "It does not appear from injections that tubercles are themselves provided with vessels, and hence they have been called morbid secretions, perhaps more properly than adventitious textures." *

This argument assumes that no vessels can be so small, even in the most delicately organized parts, as not to admit, and be brought into view by the fluids employed for anatomical injection. But the point assumed is far from being established. It is contrary to the opinions of some of the highest authorities in physiology and practical anatomy. Thus the late Dr. Gordon, of Edinburgh, in his esteemed work on

* Outlines of Pathology, 1832. 
General Anatomy, observes, " At last, however, after gradually diminishing as they divide, all the capillary arteries are seen to terminate in one or other of two ways; they either pass distinctly into the capillary branches of veins, or end abruptly unconnected with any other vessel. Whether in this latter case, however, the arteries do really terminate where they seem to do, is very doubtful. Perhaps they are continued much farther, and yet are imperceptible from their minuteness, even by the most powerful microscopes."

In the healthy condition of the articular cartilages no vessels can be discerned, even after the finest injections. Yet in some cases of inflammation red vessels have been distinctly seen traversing their substance *. That these should have owed their existance to the inflammation, is inconceivable. Whereas nothing is more conformable to analogy than to suppose, that the cartilages are, in their healthy state, supplied with nutrient vessels too minute to carry red blood or to admit the coarse injections of anatomists; and that, when the cartilages inflame, their vessels, like those of other inflamed parts, dilate so as to acquire a distinctness not naturally possessed. This is the inference drawn by many of the most eminent pathologists and anatomists. "In the adult person," says Sir Benjamin Brodie, refẹrring to the articular cartilages, "these canals for the distribution of blood are not perceptible. This proves that they are very minute, but not that they are altogether wanting."

- See Sir Benjamin Brodie on the Diseases of the Joints, and Bichat's Anat. Gen. 
Speaking of cartilage in the adult, the late Dr. Gordon remarks, "There is no doubt of its being vascular; but I do not know of any method by which its blood-vessels can be injected after death. These vessels therefore must be very minute." *

The recent successes of Mr. Kiernan afford ground for hope, that by improved modes of injection structures hitherto intractable may hereafter be made to display their organization. At present, the impermeability to injections cannot be admitted as proving the absence of vascularity in parts whose vessels must be presumed to be so diminutive as those which nourish pulmonary tubercles.

But I shall now show that, in the case of pulmonary tubercles, injection has never been fairly tried.

It was discovered by Rusch, that the nutrition of the lungs is performed mainly by the bronchial arteries. Reisseissen has lately observed, that those branches of the bronchial arteries, which ramify through the aircells, receive anastomoses from the pulmonary arteries, and terminate in the pulmonary veins. So porous are these minute vessels and the air-cells which they traverse, that their contents are freely exposed to the influence of the air; and thus the blood of the bronchial arteries, though mixed with the venous blood of the pulmonary arteries, has its purity restored in time to perform the work of nutrition; and when it passes into the radicles of the pulmonary veins, it again becomes oxygenated, before it is conveyed to the left side of the heart.

* See also Bichat's Anat. Gen. 
But the same author has shown that in those parts of the pulmonary structure which are impervious. to air, there is not this admixture of venous with the arterial blood, and that the blood by which they are nourished, is derived exclusively from the bronchial arteries, and returned exclusively by the bronchial veins. Now this is the case of pulmonary tubercles : their texture is too compact to give access to the air: their nutrient vessels, if any exist, may therefore be presumed to be solely connected with the bronchial arteries and veins: whence it is obvious, that to attempt their injection with any reasonable hope of success, the fluid should be thrown into the bronchial arteries. Instead of this the pulmonary arteries and veins have alone been resorted to, while the bronchial arteries have been neglected.

Having shown the invalidity of the evidence adduced to prove the non-vascularity of pulmonary tubercles, I proceed to give an account of seven cases in which great numbers of pulmonary tubercles of the ordinary kind were distinctly seen to be traversed by red vessels.

They had not in their symptoms differed from the generality of cases in which tubercles have been found in the lungs after death. Cough, dyspnœa, pain of chest, night-sweating, diarrhœea, emaciation, had most of them been present in all. The subjects were of all ages, 7, 15, 21, 26, 42, 61, 65. In each, the lungs presented every stage of tuberculous disease. In soine places there were transparent or semi-transparent, colourless or whitish bodies, many of them 
rounded or oblong, varying in size from that of a grain of sand to that of a hemp-seed, from cartilaginous to fleshy firmness. In other places, the bodies were nearly or altogether opaque, and of a whiter or yellowish hue; some were firm, others softened or quite liquid. Excavations had been formed, principally at the apices of the superior lobes. In two of the cases the tuberculation had for the most part assumed the form which has been termed infiltration.

In every one of these cases a great number of the isolated solid tubercles, both such as were white or yellowish and opaque, and such as were greyish and translucent, presented the following appearances. A careful section being made of the tubercle intended for examination, the cut surface was seen by a strong magnifying glass, sometimes also with the naked eye, to be traversed by continuous red lines, which were sometimes short and unconnected, but often of considerable length and making frequent ramifications and anastomoses, quite after the manner of small bloodvessels. An intelligent friend, to whom I showed the appearance, compared it to the arrangement of vessels in an inflamed conjunctiva. On several trials we found that these red lines could not be removed by being gently scraped with the edge of the scalpel. In many instances they might be traced from the centre to the circumference of the tubercles, whence they were sometimes seen to extend into the adjacent pulmonary parenchyma, or to communicate with the vessels in the neighbourhood. There is no room for 
doubt that these red lines were blood-vessels: for such an appearance, when exhibited by solid parts, has always been considered decisively characteristic of vascularity.

In each case the number of tubercles in which red lines were visible was very great. When the portion of lung had grown stale by keeping, then, along with the red lines, there were some of a brownish red colour, and others which were dark-brown, or quite black. In all there were many tubercles in which no vascular appearance whatever was discernible. But it frequently happened that the pulmonary parenchyma, for a considerable distance around, was equally destitute of the appearance of red vessels. Indeed it may be observed of every tissue and orgar in the body, that after death its vessels are sometimes filled with red blood, at other times empty, and that some parts are reddened, while others remain pale.

Whether those tubercles in which no vessels were to be seen after death were furnished with red blood during life, may therefore be questioned. But nutrient vessels of some kind must be conceded to them. For how can it be supposed that, agreeing in all other physical characters with those in which red vessels were visible, they differed so fundamentally as to be destitute of organization? The same may be said of several cases of pulmonary tubercles, in none of which I could find vessels containing red blood.

Two of the specimens of vascular tubercles, I shewed to my very intelligent friend Dr. Sutherland junior, who favoured me with the following tes: 
timony to the correctness of the description above given.

$$
\text { CASE I. }
$$

"In a portion of the lung of Benjamin Farrer, which was thickly studded with miliary tubercles of the ordinary aspect, Dr. Kingston shewed me, to my perfect satisfaction, after a very attentive examination, that a great many of the tubercles had bright red lines, of the appearance of blood-vessels, not only at their circumference, but also traversing their interior (as was clearly seen, when these tubercles were carefully cut through the middle, in some instances with the naked eye, in others only by the aid of the microscope). These tubercles were more or less white, more or less translucent, of fleshy firmness, many of them rounded, from the size of a small shot to that of a small pea, for the most part discrete, but in some places clustered. In some of them a single bright red continuous streak was alone visible: in others there were several distinct bright red waving lines seen to ramify from a larger red trunk: in some these lines were very numerous, and put me in mind of the arrangement of vessels in an inflamed conjunctiva.

"A few of these tubercles, traversed with red vessels, I saw on the 16th, and a great many on the 17 th. On the latter day (which was the 5th after death) some of the tubercules, besides one or two thicker red streaks, displayed a distinct appearance of beautifully arborescent lines, similar to those above described, 
except that their colour, instead of being bright red, was in some instances a dingy red, in other instances a dark brown approaching to black.

"In some, the red vessels traversing the interior of the tubercles were seen to extend to, or to take their rise from the surface of the tubercles.

"Sept. 23d, 1835."

$$
\text { “A. J. Sutheriand." }
$$

\section{CASE II.}

“ On November the 28th, 1835, Dr. Kingston shewed me a portion of recent lung which exhibited well characterized tubercles in all stages. Some were translucent and slightly white or greyish with black striæ. Others were less hard, were white or yellowish, and opaque or semi-opaque. Some were translucent and slightly white at the edges; yellow and opaque at some portion of their interior. Their size varied from that of a millet-seed to that of a small pea. Some were discrete, others clustered.

" Of two of the tubercles, which were whitish, semi-opaque, and of rather more than fleshy firmness, Dr. Kingston made a careful section, and then shewed me, by the aid of a powerful magnifying glass, very distinct red lines traversing the cut surface, in some instances seen to ramify, in one instance the ramification seeming to proceed from a thicker red point near the centre. In some places the red lines extended into the interior from the circumference. The appearance was most distinctly that of vessels; and, still more strongly than in the former case, reminded me of the arrangement of vessels in an inflamed con- 
junctiva. Dr. Kingston made a seeond section of one of these tubercles, and upon the second surface I again saw red lines disposed after the same manner; but more minute.

"I was prevented by a previous appointment from waiting to examine more of the tubercles in regard to their vascularity: but feel perfectly satisfied, that in both the tubercles which I did examine there were continuous red arborescent lines traversing their interior, and extending in some instances to the circumference.

“A. J. Sutherland.”

“ 1, Parliament Street,

December 1, 1835."

The proof here adduced of the vascularity of the common pulmonary tubercle * appears to me complete in itself, and not liable to be shaken by any facts which may hereafter be brought to bear on the subject. I therefore have not deemed it necessary to ascertain the result of an injection by the bronchial arteries. Should it be found impracticable to inject the tubercles in this way, the failure could not in the least invalidate the present conclusion, as it would be referable to their extreme minuteness. Indeed, it has been observed by Reisseissen, the most successful injector of the vessels of the lungs, that even those

* I have as yet examined but few cases of the tubercles of other organs in respect to vascularity. But in one of the seven cases above analyzed, both the bronchial and the mesenteric glands contained yellowish, opaque, cheesy, somewhat rounded tubercles, about the size of hemp-seed, which were distinctly traversed by red vessels. 
branches of the bronchial arteries which naturally ramify in the air-cells are incapable of admitting the finest injection. On the other hand, should the tubercles receive the injection, such evidence might not by all be considered decisive, as in the dead body thin injections are found to penetrate where no vascular communication is believed to exist.

If the fact which I have been endeavouring to establish be admitted, there is no longer any difficulty in explaining the changes of colour and consistence which take place in the interior of pulmonary tubercles during the several stages of their progress, and the frequent commencement of these changes in their centres. Whereas, under the supposition that tubercles are destitute of organization, these phenomena are inexplicable, or at least have received no explanation generally satisfactory to the profession.

\section{II.}

It was held by Tralles, nearly a century ago, that they sometimes consist of air-cells distended with morbid secretion, which has gradually solidified and acquired the various appearances presented by tubercles in their several forms and stages. During the last twenty years, observations in support of this opinion have been brought forward, first by Magendie and Cruveilhier, and since by Andral and Dr. Carswell.

Magendie was led to the conclusion by a dissection of lungs previously desiccated : but Cruveilhier thinks the process of desiccation liable to mislead the ob. 
seirver by tearing and variously altering the appearance of the pulmonary vesicles.

Cruveilhier himself, in his first publication* on the subject in 1821, merely affirms that in the lungs of oxen some of the pulmonary lobules were so crowded with tubercles that one would say a tubercle corresponded to each air-vesicle: but he offers no proof that the air-vesicles had not been pushed aside, compressed, and atrophied by the development of tubercles in the intervesicular cellular tissue. In his second essayt in 1826, he relates a case in which, mercury having been injected into the trachea of a dog, the animal gradually wasted, and died in a month, and the lungs were found loaded with bodies exhibiting all the physical characters of miliary tubercles, and having each a globule of mercury in its centre. There can be little doubt that they were situated in the air-cells: and if they be admitted to have been true tubercles, they afford a strong analogy in favour of the supposition, that in at least some of the cases in which tubercles are produced by ordinary causes, they have this situation. But the identity of these with tubercles is denied by Gendrin: and Roche, Rochoux, Broussais, Laennec, Lobstein, and others, remained unconvinced.

Andral detected liquid or semi-liquid white opaque matter in extremely minute bronchi. But its tuberculous character may by some be doubted; and at

* Médecine éclairée par la Physiologie.

+ Nouv. Bibl. Med. 
all events, before we conclude that it was originally secreted into the vessels where it was found, we require evidence that it had not been derived from adjacent tubercles which had formed a communication with the bronchi by ulceration.

Dr. Carswell, whose skill in pathological investigations is generally allowed, has given delineations of portions of human lung, in which bronchi, some of them very minute, appear to be filled through several ramifications with solid tuberculous matter. He thus succeeded in that which Cruveilhier had tried in vain, and which Andral had considered impossible. Andral observes, " this seat of tuberculous matter cannot be established, except whilst the tuberculous matter is in its incipient state, that is to say, liquid or semi-liquid; then only the facility with which it may, by simple pressure, be expelled from the cavity containing it, permits one to recognize, that that cavity appertains to a bronchus, a fact which it is no longer possible to establish at a later period, from the difficulty of extracting the tuberculous matter entire and without laceration."* But Dr. Carswell's observations, however valuable, do not decisively prove that the tuberculous matter was originally deposited in the bronchi. For, though solid at the time of death, it may at one time have been liquid or mixed with liquid, and in that state have found its way into the bronchi, either from vomicæ or from softened tubercles in the neighbourhood, and may afterwards have had its fluid particles absorbed. Indeed, in several of Dr. Carswell's speci* Clin. Med. 
mens of bronchi filled with tuberculous matter, these bronchi are represented as being in immediate communication with large excavations containing tuberculous matter of various consistence.

The evidence, therefore, in favour of the opinion that the bronchi and air-vesicles are sometimes the seat of tubercles, is still considered by many as incomplete, and as needing addition and support from further investigations. Dr. Gregory, among others, in the recent edition of his Elements of Medicine, adheres to the opinion that pulmonary tubercles " are situate not in the air-cells, but in the proper cellular texture of the lungs." The observations I am about to relate, in conjunction with some of those just referred to, have convinced me that pulmonary tubercles sometimes originate in the following alteration of the air-cells and their secretions. Antecedently to the appearances by which tubercles are commonly recognized, the air-cells in question become thickened and distended with morbid mucus. Their parietes continue to thicken, and their contents gradually solidify, till at last a total obliteration of their cavity is effected, and there result a number of solid, white .or grey, more or less opaque bodies, frequently of rounded form, such as have received the appellations of miliary tubercles and miliary granulations.

In October, 1834, I witnessed the inspection of a -subject whose lungs presented the following appearances. In the upper lobe of the right lung were several tough, grey capsules. Some of these were filled with matter which, at the circumference, was 
very tough, black, and opaque; but at the centre, partly of a black, partly of a dirty-white colour, opaque, of a caseous softness, in some places minutely granular, held together by cellular substance. Other capsules were filled altogether with the soft matter last described. At the roots of the lungs were some similar masses, and also several capsules enclosing hard earthy nodules. One of the latter, however, had perforated both its cyst and the parietes of a large adjacent bronchus, and was projecting naked into its cavity. Very thickly disseminated through both lungs, were bodies considered by all present to be incipient tubercles. They were in general of a somewhat rounded or oval form, from the size of a grain of sand to that of a mustard-seed, some transparent and colourless, others whitish and semi-opaque; they felt hard and quite distinct from the adjacent pulmonary structure, as the finger was passed over them. On further examination, I found that each of these bodies consisted of a tough, nearly transparent cyst, filled with fluid, which in some was white, semiopaque, thick and viscid, in others was thinner, transparent, and colourless. The neighbouring bronchi were filled with mucus of similar appearance, and in several instances a minute bronchus so filled could, on dissection, be distinctly seen to terminate in one of these vesicles. The bronchial mucous membrane in these parts was thickened; in some places white and semi-opaque, in others reddened and softened.

There could be no doubt that the tuberculoid bodies were continuous with the bronchi, were por- 
tions of the air-passages : and thence I learnt that the terminations of the air-passages, the air-cells as they are termed, are liable to become thickened, dilated, and filled with thick mucus, and that they then assume an appearance nearly resembling that of tubercles both to the eye and to the touch.

All that was wanting to render these distended thickened vesicles identical with miliary granulations or miliary tubercles, was an obliteration of their cavities. That their cavities may sometimes be obliterated, either by an increased thickening of the parietes, or by gradual inspissation and solidification of their contents, is divested of all improbability by the frequency of such changes in the other canals and receptacles of the body: though,' as* the texture, function, and circumstances of the air-cells are very peculiar, the precise nature of their lesions and their degree of liability to various diseases cannot be expected to be uniformly similar to those of any other structure. Obliteration of the serous and synovial cavities by secretions gradually concreting into thick solid masses and connecting their opposite surfaces, are among the most common of morbid appearances. Thickening of their parietes is no less so. The mucous canals are comparatively seldom obliterated by secretions : yet cases are not very rare, in which the bronchi are found choked up with what are termed bronchial polypi ; and in a case of pulmonary tubercles and ulcerations of the colon, $I$ found the appendix vermiformis enormously distended by a

* See Andral, Anat. Pathol. T. II. p. 462. 
firmly adherent mass, which towards the circumference was white, opaque, quite solid, and disposed in concentric laminæ, towards the centre gradually losing its colour and consisting of a firm jelly intersected by cellular tissue. On the other hand, it is well known how frequently the urethra and certain parts of the alimentary canal are thickened, and the several tunics of the bronchi have been found so much so as to render their channels almost impervious. The thickened parietes of dilated bronchi are also converted sometimes into cartilage, thus presenting an analogy to the cartilaginous appearance of some tubercular granulations. The veins, arteries, and lymphatics, though less frequently examined, have been found obliterated both by thickening and by their secretions.

It was, therefore, rather the fulfilment of an anticipation than a matter of surprise, when some time afterwards cases came under my observation, in which there was a gradual transition from the thickened distended air-cells above described to the solid body which is termed miliary tubercle; and in which therefore the two could be identified as constituting different stages of the same disease. As my time has been too much subdivided to permit a very particular search for cases bearing upon the present point, I have only met with two which combined all the circumstances requisite to make the chain of proof complete. In these were presented the whole of the following series of particulars.

1. Excavations, principally at the apices of the vol. $\mathbf{x x}$. 
lobes, of the ordinary appearance of those which accompany tubercles.

2. White or yellowish, opaque or nearly opaque bodies, appearing in the section of the lung to have a somewhat rounded or oblong form, some nearly liquid, others of various degrees of firmness up to that of the pancreas.

3. Firm bodies differing from the latter only in having less colour and more translucency: many of those which at the circumference were very translucent and nearly colourless, having in the centre a small, yellow, opaque speck : others having a whiteness and tendency to opacity, slight towards the circumference, gradually increasing towards the centre. Some of these bodies, upon a minute examination, were found to be cylinders with a bulbous extremity, containing in some instances a yellow, opaque particle.

4. Bodies which did not to the eye differ from the preceding, some being nearly colourless and very translucent throughout, others of a whiteness and opacity gradually increasing towards the centre, the greater number of a somewhat rounded or oblong form: feeling hard also as the finger was passed over them while they lay in the lung. Upon a careful examination it was found that these consisted of membranes of various thickness, of a white or greyish colour, filled with colourless or whitish, translucent, very viscid fluid, having all the appearance of mucus : and in numerous instances it was observed that the adjacent bronchi were filled with mucus of the same 
appearance. Minute bronchi distended with this mucus could often be seen proceeding for a considerable distance, and at last terminating in one of the vesicles filled with a similar fluid. There could, therefore, be no doubt that the vesicles were portions of bronchi, or of the cells in which they terminate, greatly distended with mucus. Particles of yellow, opaque, friable matter were, in some instances, contained in the fluid which exuded from the vesicles. Some of these bodies, which at first had the appearance of being single vesicles, were, on a closer scrutiny, discovered to be clusters of smaller ones.

5. Bodies forming a transition between the third and fourth groups : in which the central cavity filled with mucus still remained, but had been greatly diminished by the concentric thickening of the parietes. These bodies, likewise, were in several instances much elongated, having all the appearance of minute. bronchi thickened.

There appears no room for doubt that the vesicles. and solid tubercles were but different stages of the same disease ; that they equally consisted in an alter-. ation of the minute air-passages, which at first became somewhat thickened and distended with their secretions; and were at last totally solidified, partly by the concentric thickening of their parietes and partly by inspissation of their contents.

While such may be inferred to be sometimes the origin of pulmonary tubercles, it cannot be supposed that the alteration of the air-cells, with which in these cases the affection commenced, invariably pursues 
this fatal course. The point hardly admits of direct evidence. But it is probable from analogy, that while in some cases the state of the constitution is such as to render abortive all attempts to remove the affection, or to check its tendency to degenerate into tubercles and vomicæ, there are others in which the parts regain their natural condition.

This view of one of the modes in which tubercles originate may reflect some light on their etiology. The school of Bayle, Laennec, and Louis, refer them almost altogether to a particular vice of constitution. Others, while they allow that the complaint attacks those alone whose constitutions are predisposed, maintain that local agents have often a great influence, and excite the disease in many, who, though the diathesis existed, would otherwise have escaped. Of the latter, they consider a lingering inflammation of the air-cells and bronchi as among the most frequent and most powerful. But, though the symptoms first observed, and their reputed exciting causes are often those of bronchitis and peripneumony, it cannot be inferred that the tubercles were consecutive: they may have pre-existed, as they have often been found, where neither the patient nor his attendants had noticed any symptoms indicative of their presence. Little doubt will, however, be entertained that these inflammations may be instrumental in determining their production, if it be admitted that tubercles are often nothing more than minute bronchi and the cells in which they terminate, thickened and distended with morbid secretion; since this alteration is just 
such as a lingering bronchitis might in some constitutions be expected to produce, and one which cannot with certainty be referred to any other mode of action. Our present conclusion affords, likewise, a more satisfactory explanation than any other, of the great frequency of pulmonary tubercles among those who breathe an atmosphere subject to vicissitudes, or contaminated with irritating vapours or particles.

It is, perhaps, in a certain number of cases only, that pulmonary tubercles have this origin. If so, future observations will probably point out in what other ways they may originate. When the constitutional and local circumstances which distinguish the several species of phthisis from one another are understood, and when the signs by which during life they may be discriminated are ascertained, each may be found to require a treatment in some respects peculiar to itself, and much of the seeming discrepancy which now subsists between the experience of different practitioners may thus be satisfactorily explained away.

III. It was formerly the opinion of the best observers that pulmonary phthisis was not unfrequently cured after ulceration had taken place. But the existence of ulceration in the cases cured was inferred from the presence of circumstances which at last were discovered to be often unconnected with it: and thence a general doubt arose, whether the reporters of these cures had not mistaken for ulceration of the lungs other affections of a less fatal character. 
Laennec has lately adduced the evidence of dissection in support of the old opinion. He collected three cases within a few months, in which pulmonary excavations had been healed either by an adhesion of their opposite surfaces, or by the formation of a lining membrane similar to those which naturally protect the internal surfaces of the body; and in which, as there remained few or 'no tubercles in the earlier stages, the disease might be considered as nearly, or altogether at an end. But in these and a few similar cases since observed, a very small portion only of the lungs had been attacked. Hence Andral remarks, "Tout en reconnaissant que des excavations tuberculeuses peuvent se cicatriser, nous avouons que dans le plus grand nombre des cas, cette cicatrisation p'est guère utile au malade, en raison de l'existence simultanée d'un grand nombre d'autres tubercules. L'oblitération d'une caverne ne pourrait être avantageuse que dans les cas òu il n'existerait qu'un seul tubercule, comme nous venons d'en rapporter un exemple; ou bien, si, consécutivement à la cicatrisation de la caverne, les autres tubercules, existant en petit nombre et entourés d'un parenchyme sain restaient stationnaires dans leur développement." * And Dr. James Clark, in his recent work, affirms that "No Physician acquainted with the morbid anatomy of phthisis can for a moment indulge the hope that we shall ever be able to cure what is usually termed ' confirmed consumption,' if we except the small proportion of cases in which the tuberculous

* Clinique Médicale. 
deposit is confined to a very limited portion of the lung."

No instance has been recorded, and even by Laennec no instance has been contemplated as possible, in which a tuberculous affection, so extensive as to have disorganized the whole of one lung and a fourth part of the other, had been healed. Yet this is what had occurred in the following case.

A coachman, aged 49, was admitted into St. George's Hospital in August, 1834, for a wound on the calf of the right leg from the kick of a horse. It did not confine him to bed long, and was cured in about four months. He made no complaint of his chest to the surgeon who attended him; but from the nurses of the ward, and the patients who slept next to him, I learnt the following particulars. He had an occasional severe fit of coughing, with some expectoration in foggy weather, but was often not heard to cough for many days together : never complained of pain at the chest, palpitations or dyspnoea, but was observed, while speaking, to take breath rather oftener than was natural: never required to be propped up in bed; lay generally on the left side, though sometimes on the right and sometimes on the back: was angry when once it was hinted that he was asthmatic. He did not sweat at night: required rather more than the usual allowance of bed-clothes to keep him warm. He eat the whole of the "ordinary diet" with apparent appetite : used to be dressed and sitting up the greater part of the day, and for some time before he left the hospital could 
walk three or four miles without fatigue or any ill effect.

Having in the beginning of January been dis- . charged as cured, he, a few days afterwards, was drenched by a heavy shower, and on the 24th was brought back to the hospital, complaining of violent pain at the loins and hypogastrium, suppression of urine for two days, severe scalding whenever a few drops were passed, and a great itching at the glands. Five days afterwards there supervened severe headache, delirium, ptosis and strabismus of the right eye, with dilatation of the pupil. He died on the twelfth day of this last attack, during the whole of which he never coughed, nor made any complaint of his chest.

Sectio cadaveris, eighteen hours after death.The surface was in general pale, the face, trunk, and lower extremities were slightly œedematous. There was no emaciation: the parietes of the chest and abdomen were moderately fat: the arms and thighs were well developed, the legs were not thinner than might be natural to a person of his occupation, and who had been inactive for five months. I noticed an old trace of venesection at the bend of each arm.

There was much serum on the surface and in the ventricles of the brain, the large yessels of which were distended. The kidneys presented the characters of severe recent inflammation, both of the cortical and medullary portions, and of the lining membranes of the infundibula, pelves, and ureters. The mucous membrane of the bladder was somewhat congested, its muscular tunic was thickened, and the prostate 
gland contained lymph and pus. Thus much for the immediate cause of death.

The only other morbid appearances which, on a very careful examination, could be discovered in the abdomen were, some enlargement of the liver and spleen, and three or four very small ulcerations of the colon. A large quantity of fat was collected in the omentum and mesentery, in the appendices epiploicæ, and about the kidneys.

The left lung was loosely connected to the ribs and pericardium by a tough net-work containing a layer of fat from half to three quarters of an inch in thickness, and many inches in extent. The lung, when separated from this, was not larger than a moderate orange flattened; it had the breadth of the palm of the hand. The whole of the upper and part of the lower lobe was covered with a thick, reddish ligamentous membrane, from a line to a line and $a$ half in thickness.

The lung had totally lost its natural sponginess, and was irregularly hardened. The upper lobe was entirely converted into a large excavation, with the exception of a rind which was in general from half a line to a line and a half in thickness, and no where exceeded three lines. This excavation was capable of holding above a quarter of a pint of fluid : it was slightly divided into three compartments by intersecting bands of pulmonary substance. In the lower lobe were two cavities of the size of small plums, and there.were about a dozen as large as unshelled filberts, communicating with the former, some by large, others 
by small apertures. They were in some places within a line of the pleura, but in no place were they in contact with it. There was about twice as much of the lower lobe remaining as of the upper: they were separated from each other by a tough, somewhat vascular, fibro-cartilaginous tissue, which in some places was nearly half an inch thick.

All these excavations and the bands which traversed them were lined with membrane which was smooth, thicker than the mucous membrane of the bronchi, semi-transparent, generally whitish, but in some instances reddish, having the firmness in some places of mucous, in others of fibrous membrane. Here and there were whitish or black elevated points, generally covered by the inner membrane. Underneath there was generally a second membrane, which was whitish, fibro-cartilaginous, of the thickness of writing paper : but in a few places it was not very distinct from the tissue external to it. I observed the mouths of several large bronchi, some of the diameter of writing quills, opening into the excavations nearly at right angles with their surface, so as to have the appearance of being cut short off. Their mucous membrane was gradually lost at the edge of the excavation. At the mouth of one of the bronchi was a relic of one of the corroded cartilages, making a pointed projection into the cavity of the excavation.

One or two of the minor excavations were partially occupied by solid, but friable, granular, nearly opaque masses, which did not adhere to the surface of the excavations, and were evidently the residue of old 
tuberculous secretion, of which the fluid particles had been absorbed. The other excavations contained nothing but a slight mucous exudation; no puriform or tuberculous matter whatever.

What remained of the pulmonary structure of this lung was totally destitute of air, very tough, flabby, of grey or reddish brown colour. Each lobe contained six or eight tough, whitish, translucent capsules, of the size of pins' heads, filled with opaque, yellowish, minutely granular, dry matter, held together by cellular threads. There was also a small ramifying tube filled with the same matter. The bronchi and blood-vessels were generally much shrunk. The bronchi were lined with a reddish mucus, and their inner membrane was slightly reddened, and softened. A portion of one was dilated to four times the natural calibre: its lining membrane was similar to the rest, except that it was more reddened, and here and there gathered up into transverse ridges, very characteristic of bronchial dilatations.

At the right side of the chest the pleuræ were in a few places adherent by tough membrane, which, at the edge of the lower lobe, contained a mass of fat. The condition of the right lung differed widely from that of the left. It was larger than is usual. It contained no excavations whatever. About three fourths were perfectly healthy, except that a good many of the air-cells were enlarged. The remaining fourth was taken up with solid masses, disseminated in considerable numbers through the upper and middle lobes, very sparingly through the lower one. 
Their size varied from that of a mustard-seed, to that of a filbert. There was one whitish, semi-transparent, firm tubercle of the size of a mustard-seed, which appeared to be contained in the thickened dilated extremity of a bronchus. A great many consisted of capsules filled with matter of different appearances. Their contents were in a few instances a congeries of granules, of the size of millet-seeds, of caseous consistence, generally yellow and opaque, but in one or two instances translucent and whitish, here and there appearing to be connected by a cellular web. In several instances their contents consisted partly of these yellow granules, and partly of harder black matter. Then there were five or six pea-sized capsules, filled entirely with black matter, of considerably more than caseous hardness. But the lung was still more thickly strewed with roundish black masses, some of woody hardness, without any investing membrane. One cyst contained a white, hard calculus. The pulmonary tissue around these masses was crepitating, and in all respects healthy: Some of the bronchi of this lung contained a whitish or reddish viscid mucus : and the cartilages at the divisions of some of the small bronchi were much thickened.

The trachea presented a healthy appearance, except that its follicles were somewhat unduly developed. The bronchial glands were of moderate size; some were black, and exuded an inky fluid. The heart was adherent to the pericardium at its base. There was a considerable quantity of fat on its superior surface and around its edges. Its size was 
natural. Each of the left cavities could have held only about six drachms. The right ventricle was twice as large as the left, and the right auricle three times as large as the left auricle. At the upper part of the fossa ovalis there was a valvular communication between the two auricles, capable of admitting the little finger, and so formed as to permit the passage of the blood only in the direction from right to left: contiguous to this were a number of minor apertures, altogether equivalent in calibre to a crowquill.

In this case the whole of one lung and a quarter of the other had been incapacitated by the disease. The tuberculous débris found in one or two of the minor excavations, and the remaining yellow, opaque, friable tubercles, few and encysted as they were, will be generally considered sufficient evidence of the nature of the lesion which had produced the excavations. The freedom of the other excavations from tuberculous and purulent matter, and the perfect and healthy appearance. of all their lining membranes, shewed that they were no longer in a state of ulceration, and could now occasion no ill effects beyond what resulted from the loss of so large a portion of the respiratory organ, from a susceptibility common to newly formed membranes, and from the difficulty of ejecting any unusual secretion of mucus. The encysted state of the few tubercles which remained, proved that they had withered, and were incapable of exciting irritation. The carbonaceous masses into which those of the right lung had 
for the most part been converted, are admitted to be nearly innocuous.

These inferences are corroborated by the absence of all habitual chest-symptoms, except the necessity of frequently taking breath while speaking, which the diminished capacity of the lungs for air rendered inevitable. The latter circumstance likewise enfeebled in some degree the power of generating heat; and must have induced some general weakness of constitution, and a predisposition to inflammatory attacks, such as that by which the patient was eventually carried off. The susceptibility of irritation with which newly formed membranes might be expected to be endued, was indicated by the coughing and expectoration in foggy weather: the paroxysms in -which the coughing sometimes occurred proceeded from the difficulty of ejecting the mucus which on such occasions was secreted into the excavations.

The direct communication which existed between the auricles, though in some respects injurious, had in this case the advantage of helping to preserve the lungs and the venous system in general from the congestion which the diminished calibre of the pulmonary vessels tended to produce. The disappearance of that vice of constitution which is connected with tuberculous disease, was fully proved by the freedom from all tubercles in the ordinary conditions, notwithstanding that a fortnight before death a potent exciting cause had been applied,- by the quantity of fat which was accumulated in many parts of the body, and by 
the constitutional vigour evinced in the recovery of health, flesh and strength, after so severe a wound.

Although there sometimes exist marks which satisfactorily indicate the healing of pulmonary tubercle, it is far more common to meet with appearances which, though they may often have had a similar origin, want the peculiarities necessary to distinguish them from the vestiges of other diseases. Unless the symptoms during life have been very characteristic, the nature of such cases is left in doubt. When it is considered for how few years these traces of past disease have been understood or attended to, how often they are ambiguous, and how liable to be overlooked, it will not appear unlikely that the proportion of cases in which pulmonary tubercles are actually healed is many times greater than the proportion in which the cure has been demonstrated. 